\title{
Making the Case for Adopting and Evaluating Innovative Pedagogical Tech- niques in Engineering Classrooms
}

\section{Dr. Sohum A Sohoni, Arizona State University, Polytechnic campus}

Dr. Sohoni is an Assistant Professor in Engineering and Computing Systems at Arizona State University's College of Technology and Innovation. Prior to joining ASU, he was an Assistant Professor at Oklahoma State University. His research interests are broadly in the areas of computer architecture and performance analysis, and in engineering and computing education. He has published in ACM SIGMETRICS, IEEE Transactions on Computers, the International Journal of Engineering Education, and Advances in Engineering Education. His research is supported through various internal and external funding agencies including the National Science Foundation. He is a popular and well-respected instructor, and has received many teaching awards including the Regents Distinguished Teaching Award in 2010 at OSU.

\section{Scotty D. Craig, Arizona State University}

Scotty D. Craig is an Assistant Professor in the Human Systems Engineering Program within the Fulton Schools of Engineering at Arizona State University. Dr. Craig received his Ph.D. in Experimental Psychology with a focus in Cognitive Psychology from the University of Memphis in the Department of Psychology and a Post-Doctorial Fellowship at the Pittsburgh Science of Learning Center. His goal is to provide cutting edge research at the intersection of human cognition, technology, and the learning sciences which provides solutions to real world problems within education and training. His current research focuses on improving learning with higher-level cognition factors such as discourse and cognitive affective states through the use of virtual humans within technological environments. More information on Dr. Craig's work can be found at www.cobaltlab.org. 


\title{
Making the case for adopting and evaluating innovative pedagogical techniques in engineering classrooms
}

\begin{abstract}
There is a large body of literature available on effective teaching and learning both within the American Society for Engineering Education's (ASEE's) conference proceedings and journals, and in wider outlets. One primary goal for ASEE is to get engineering educators to adopt effective pedagogies in their classrooms. However, this is not happening at the rate or scale that the community is hoping. Furthermore, even in cases where it is happening, there is often limited evidence of correct implementation (e.g. techniques are implemented as intended or have the desired impact in the classroom).
\end{abstract}

Our hypothesis is that, even for faculty who are interested in adopting innovative teaching methods, research findings and techniques that are not within their specific sub-discipline are difficult for them to implement and evaluate. These would-be adopters might appreciate some of the theory or the general learning principles from these publications, but they are often unclear on exactly how the principles can be applied within their classrooms. More importantly, they may not know how to assess the impact of the changes. Setting up research studies involving human subjects, designing the classroom evaluations, or simply designing the right questions to ask within assessments, are activities most practitioners are not trained in. Most practitioners may perceive that there is no time to implement these principles and evaluations. Thus, there exists a gap, even between most literature in engineering education and what can translate into classrooms. We believe that specifically focused, discipline-based, or even course-granularity based guiding papers are necessary to provide educators the tools and the confidence to employ effective teaching techniques and evaluate the impact of these techniques.

This work, a collaboration between a computer architect who has expanded his research into engineering education, and a cognitive psychologist who specializes in the learning sciences and educational technology, aims to provide an example of such a 'guiding paper'. As an illustration of the kind of specific information and tools necessary for broader adoption, we present details of an experimental design, the pre-post test questions, and a discussion of the choices we had and the decisions we made. In this example scenario, we propose to investigate the impact of an intervention in a computer organization course. By analyzing a previous experimental setup, we will illustrate specific lessons learned that could facilitate the implementation and evaluation.

\section{Importance of Translational Research}

A number of books ${ }^{1,2}$, research papers ${ }^{3,4,5,6}$, and reports ${ }^{7,8,9}$ point out the non-adoption or nontranslation of research-based instructional practices, and the phenomenon is often known as the 
valley or chasm of death. Research on barriers to change $\mathrm{e}^{3,4,10,5,11}$ has revealed a variety of reasons for the valley of death for educational innovations, and there has been a strong push to investigate solutions to this problem. Indeed, the description of programs sponsored by the National Science Foundation, such as Improving Undergraduate STEM Education (IUSE:EHR) and IUSE/ Professional Formation of Engineers: REvolutionizing engineering and computer science Departments (RED), emphasize the need for translation and investigating the causes of non-translation.

From a broader scientific perspective, it is important that practitioners implement and test research findings within their specific areas. Learning based research is conducted on a sample of the overall population of students. The practitioner applications work toward establishing the finding's robustness and add to the finding's causal generalization ${ }^{12}$. In essence when practitioners take a research finding and implement it into their class, this extends the external validity of the finding by extrapolating the finding to a new set of students, classrooms, and domain areas. If adequately tested and reported, this provides evidence both for when a finding works, but also when it does not. This information can be essential for enhancing understanding of the causal explanation underlying the effects.

\section{Barriers to Research/Classroom Transitions}

In general, the lack of translation of educational innovations can be attributed to various causes, broadly in the three categories: systemic, individual adopter, and innovation ecosystem, as shown in Figure 1. On the systemic side, there is faculty reward structure that typically promotes research over teaching or rewards 'more' teaching instead of evaluating teaching quality, situational and environmental constraints to adoption either curricular or related to infrastructure, push-back from students and reluctance on administrators' part to support the innovation infrastructure or from the point of understanding student complaints while an innovation is perfected at their institution. From the potential adopter's perspective, there might simply be a lack of interest, a skepticism of the effectiveness of an educational innovation, pressure from the reward structure to focus on research rather than teaching and learning, fear that the innovation

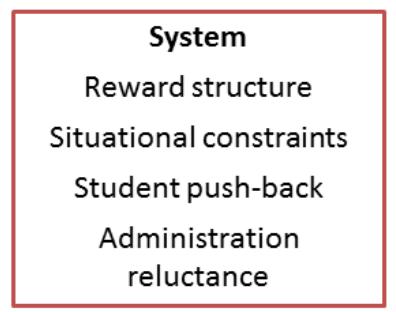

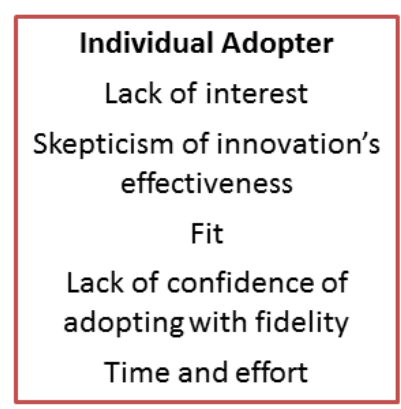

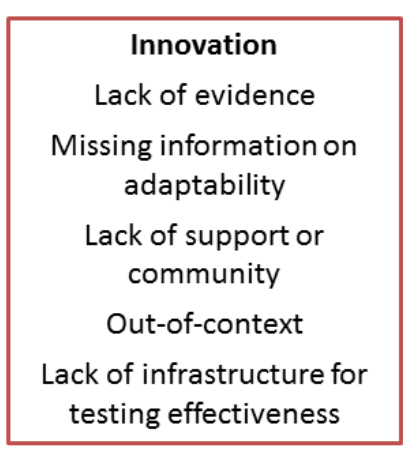

Figure 1: Typical barriers to adoption of educational innovations, categorized into systemic problems, individual concerns, and issues stemming from the dissemination efforts of the innovators. 
might not be a good fit for their classroom, reservations about their ability to practice the innovation as intended, and time and effort towards implementation. From the innovator's side, there might be shortcomings with the innovation or the ecosystem surrounding the innovation, such as unclear directions on how to adopt, lack of evidence showing effectiveness of innovation, no information on the time, effort and the difficulties encountered while implementing the innovation, lack of (customer) support, and lastly, no support to test the effectiveness of the innovation in new contexts.

It is clear that factors from each of the three categories influence each other, and in the last few years various reports ${ }^{13,14}$ and research studies ${ }^{5,15,6}$ have called for changes at the systemic level in higher education, especially in the STEM fields. We welcome these initiatives, and we hope that they bring about systemic changes. However, we believe that there is an important gap in the various efforts to bring about systemic changes, and these changes should be supported by efforts that can be classified as discipline-specific or sub-discipline-specific, so that potential adopters have a support ecosystem that contextualizes educational innovations and facilitates their adoption and evaluation. Contextualizing at the course level will be especially effective, and is in our view essential for facilitating the translation of educational innovations. For example, a well-designed pretest posttest for computer architecture with built-in flexibility to incorporate specific course outcomes at different institutions for a course in computer architecture will serve the following purposes.

1. Provide an educational innovator with a measure for testing the effectiveness of the innovation, without having to invent and validate a new one.

2. Provide a potential adopter the same measure to test the effectiveness in their institutional context.

3. Add credibility to the entire project by facilitating the validation and transferability of the innovation by providing a resource for all adopters to use.

4. Enable both the innovator and the adopter to publish the classroom experiment results, thereby providing an additional reason for engaging in the innovation and adoption. This is important because quite often, faculty are faced with choosing between spending their time improving their teaching and working on research that will lead to publications.

\section{Case Study}

To illustrate the importance of building assessments such as pretest posttests and describing research methods in the context of particular classes, we analyze an article ${ }^{16}$ on a computer architecture learning platform. The article describes the platform in detail, provides some information on how it can be used in a few computer engineering classes, and then presents a pilot study that evaluates the platform's effectiveness in the context of a computer architecture class. The study used pretest and posttest assessment as a quantitative method for measuring 
changes in student knowledge in two iterations of the course, one with limited use of the platform and one in which the course was organized as a semester-long project based entirely on the platform. It supplemented the quantitative assessment with qualitative assessment based on focus-group interviews with students. The pre-post measure used is presented in Appendix A. The guiding questions for the focus group interviews are listed in Appendix B.

This article serves two purposes. First, an article of this type could be typical of a type that an instructor might find and attempt to determine if the same methodology could potentially work within their class. Additionally, the article also serves as an example of the type of study that could come out of a classroom implementation if adequate assessments are added to the teaching implementation. In this review, we will first give an overview of the article and findings addressing some points of interest that instructors can use when evaluating articles covering instructional innovations. We then use the current study to warn against potential pitfalls that instructors should worry about when implementing a new instructional innovation into their course with an evaluation component.

\section{Article Summary: Progressive Learning Platform (PLP) evaluation study}

A study testing the impact of PLP in a computer architecture class used a mixed methods case study design. PLP is a platform that consists of an integrated development environment for the PLP assembly language, an open source Verilog description of the PLP hardware that is synthesizable on an FPGA, and a simulator/visualizer that simulates the processors as well as the input/output on Diglient's Nexys 3 development board ${ }^{17}$. PLP was designed to allow students to make the connections between hardware and software, and to provide the means for active and interactive learning in a number of computer engineering classes, especially computer organization and computer architecture classes. As constructivism was the epistemological framework guiding the research, free-flowing focus groups that encouraged extensive participant interaction and evolving perspectives were used. The researcher also kept field notes that included observations and emerging insights. In addition to the qualitative data, this study used pre- and post-test assessment as a quantitative method for measuring changes in student knowledge.

\section{Qualitative Data}

The focus group allowed students to voice any opinions about their experiences in the course while using a set of guiding questions. Sessions were audio-taped and transcribed. Open coding and researcher memos served as a primary data analysis methods with particular attention paid to emerging patterns and themes. Data collected into four primary themes as reported below. 
Overall, students in the focus groups characterized their experience in the classes as "different", in a positive way, from previous engineering course experiences. The focus group members specifically noted four observable themes that they felt improved their understanding of Computer Architecture and Computer Engineering as a whole.

Building and Bridging Knowledge: Participants noted that the course concepts were serial and had a backwards dependency, including into previous courses in the Computer Engineering curriculum. Students had to understand the previous material (specifically in lab assignments) in order to proceed to the next. This dependency was not artificial (such as not being allowed as per the syllabus to proceed until previous lab work was accomplished), but rather was a natural progression of learning the assigned material.

Increased Levels of Communication: Participants noted that the use of PLP required and facilitated an increased level of communication. Requirements for inter-team communication were reported as “much higher.” Communication "with more than just your partner” was expected.

Increased Student Engagement: Participants generally agreed that students were more engaged with the course content, both because the format of the course facilitated engagement and because of student interest in the course, project, and PLP.

Perceived Authenticity: The authenticity of the learning process, or the degree to which it mimicked the real world, was a prominent factor of the use of PLP on which numerous students commented. Reports collected into two major themes related to authenticity of task and authenticity of environment.

\section{Quantitative Data}

A pre/post tests design was used to evaluate the efficacy of PLP in the classroom. The pre/post tests were identical to each other and administered at the beginning of the first lecture of the semester, as well as with the final examination (or last lecture in courses that had no final examination) at the end of the semester. The tests consisted of a number of questions designed to cover all listed course objectives. The tests were administered in 2010 and 2011, with the 2010 class having minimal exposure to PLP and the 2011 class developed entirely around PLP-based projects. A subset of test questions (6 out of 10) is explicitly covered by the PLP system.

The success of the use of PLP in the classroom was determined by comparing pretest and posttest scores. Specifically, this evaluation focused on finding out if PLP's use impacted students' knowledge of the relevant general course material and if the use of PLP in the classroom impacted knowledge of concepts explicitly covered by PLP. Tests were scored by 
calculating the mean, standard deviation, and standard error mean of the overall test and the subset of questions identified as being explicitly covered by PLP. The overall test calculations included the PLP questions. A paired dependent t-test design was used to analyze the results. Paired dependent t-tests are a repeated measure design. Thus, it is used to examine mean differences of test scores between two waves of assessments on the same participants. Table 1 shows the mean, standard deviation, and standard error mean for each sample set.

\begin{tabular}{|c|c|c|c|c|c|}
\hline Class / semester & Pre/post test & Mean & $\mathrm{N}$ & $\sigma$ & Std. error mean \\
\hline \multirow[t]{4}{*}{ ECEN 4243 Spring 2010} & Pre (overall) & 5.04 & 25 & 1.51 & .303 \\
\hline & Post (overall) & 6.88 & 25 & 1.67 & .333 \\
\hline & Pre (PLP-specific) & 1.72 & 25 & 1.14 & .227 \\
\hline & Post (PLP-specific) & 3.4 & 25 & 1.44 & .289 \\
\hline \multirow[t]{4}{*}{ ECEN 4243 Spring 2011} & Pre (overall) & 3.33 & 33 & 1.915 & .333 \\
\hline & Post (overall) & 5.76 & 33 & 2.21 & .384 \\
\hline & Pre (PLP-specific) & 1.50 & 33 & 1.37 & .239 \\
\hline & Post (PLP-specific) & 3.51 & 33 & 1.52 & .265 \\
\hline
\end{tabular}

Table 1. Means, Standard deviations, and standard errors, as presented $\mathrm{in}^{17}$

Table 2 shows the difference in mean, and t-test values from each of the studied courses. The ttest values for each of the courses indicate a significant difference, which implies that students in the course had a positive and significantly different understanding of the course objectives at the end of the course than at the beginning. This is expected of both a traditionally taught course and one that uses PLP. A subset of posttest questions was measured that are explicitly and only covered by the use of PLP in the course. These too show a significant difference in mean. The implications of these results allow us to assert that the use of PLP is an effective way to teach the stated course objectives. The overall mean difference for the 2011 ECEN 4243 course was greater than the difference in mean in the 2010 data.

\begin{tabular}{|rl|c|c|c|c|c|}
\hline Class / semester & Pre/post test & Mean difference & $\sigma$ & $\mathrm{t}$ & $\mathrm{df}$ & Sig (2-tailed) \\
\hline ECEN 4243 Spring 2010 & Overall & 1.84 & 1.49 & 6.17 & 24 & .000 \\
\hline & PLP-specific & 1.68 & 1.57 & 5.33 & 24 & .000 \\
\hline ECEN 4243 Spring 2011 & Overall & 2.42 & 1.92 & 7.25 & 32 & .000 \\
\hline PLP-specific & 2.03 & 1.38 & 8.45 & 32 & .000 \\
\hline
\end{tabular}

Table 2. Mean, and t-test values from each of the studied courses, as presented in ${ }^{17}$ 


\section{Guidance for Discipline-Based Engineering Education Research Translation}

\section{Potential Pitfalls}

Most practitioners in computer engineering are most likely well versed with the scientific method. There is a strong likelihood that an understanding of concepts such as isolating variables, consistent measurement and the need to understand what is being manipulated and measured are already present. However, it is not always easy for this skill set to generalize when trying to understand research in other areas. These areas often have specific vocabulary and methodologies that can be difficult to transition and implement. Because of this, it is often necessary to reach out to other collaborators either a colleague experienced in disciplinary based education or an expert with the learning innovation itself. While this could slow down implementation, it can be essential for valid implantation and assessment within the classroom.

\section{Implementation of Research}

Mixed methodologies are often good for initially understanding an instructional innovation in a new context. The objective pretest and posttest allows the amount of learning gained to be measured. This gain allows for a quantitative measure for the impact of the innovation, answering the basic question "Did the students learn from the implementation?”. However, it is often important to identify how this learning came about. This can be done by looking at the process that students underwent during the class. In the reviewed study, this was assessed with a qualitative focus group methodology. Most practitioners, especially the members of the ECE division for whom this paper is intended, are well-versed with quantitative methods of assessment, and could be unfamiliar with qualitative methods. As part of the discussion and recommendations section, we urge instructors to think about the methods most suited for their evaluation, and to reach out and collaborate with those who have expertise in these methods.

Another point of interest is the experimental design that the authors followed. Note that the pretest posttest was administered in two consecutive years of teaching the same course at the same institution. In the first iteration, the treatment was merely introduced to the students, whereas in the second iteration, the course was entirely designed around the progressive learning platform. Comparing the learning gains from pre to post across two iterations or with a treatment and a control group is better than just performing a pretest posttest with the treatment. Having a pretest as opposed to just a posttest across two groups allows the evaluator to look for an input bias or outliers in either group.

The pretest-posttest evaluation should be the minimum that is attempted when testing the effectiveness of a new innovation into a classroom, if a reliable contribution is to be made. Any 
evaluation of an implementation is much stronger when implemented with a control condition that covers the same content.

When adopting a learning innovation within the classroom it is important to understand the context which it has been implemented within and the procedures that have been used with previously successful applications. When considering the innovation for classroom implementation, it is important to understand the differences between the context of the previous applications and your current classroom. Sometimes subtle changes (e.g., length of application or type of information being taught: Procedural and declarative) can make a big difference. Because of this is if often beneficial to consult a disciplinary learning expert. Additionally, some innovations have application summary papers for practitioners which can be consulted.

\section{Validity of Assessments}

When selecting to implement an innovation, it is important to use a form of assessment that can measure the direct classroom impact. While all classrooms already have assessments, these assessments might not be sensitive or targeted enough to detect the implementation's impact. These instructor created assessments often have not had the validation needed give ensure that 1) the assessments is testing what was created to test and 2) the items are sensitive enough to target a large enough number of concepts. In Appendix A, the question under Knowledge assessments: Familiarity is a good example of the first point. While on the surface, it looks like it can easily target if a student understand concepts. However, students are prone to overestimate the level of their knowledge ${ }^{18}$ and falsely express their knowledge level ${ }^{19,20}$. An example of the second point, can be observed within Appendix A under Knowledge assessments: Course knowledge. While the individual questions may target specific key points, as a whole they are not robust enough to cover a large amount of course content.

To ensure that a test is robust enough to show an effect of the intervention, it is important that a rigorous process is used for assessment creation. The process should start with a cognitive task analysis which will identify the knowledge from two or more subject experts. This often involves multiple rounds of interviews with experts (See ${ }^{21}$ for a review of CTA procedures). Afterward, questions can be created to target the identified concepts. However, an assessment also needs to be validated. This allows for questions that are not sensitive enough to be removed (normally through an Item Analysis procedure) and for the construct validity to be established using independent measures.

These procedures are often beyond the expertise and timeframe of a typical instructor. Because of this it is often that an in house measure (such as the one in Appendix A) is created using some form of face validity. This is not ideal and poses questionable results for generalizability if results are not found. Another alternative is to use the assessments from the original research studies if they are close enough or to search for a validated topic area test within the broader literature to pair with in house created assessments and class grades. Similar results on multiple 
measures provide stronger evidence for the success or failure of the innovation's implementation.

\section{Identifying Repositories of Educational Innovations}

It can be difficult for practitioners to find reliable information on educational innovations with evidence within a wider domain. However, the idea of presenting research on teaching and learning in the context of particular disciplines is not new ${ }^{22,23}$. Science education, Math education, and Engineering Education research communities have existed for decades. The What Works Clearinghouse from the Institute of Educational Sciences at the U. S. Department of Education is one example of a research evidence repository. The WCC works to identify studies with credible and reliable evidence of the effectiveness and disseminates summary information and free reports on the WWC website (http://ies.ed.gov/ncee/wwc/). The WCC currently has over 700 summaries on effective educational innovations and has 10500 reviewed studies available for search. Within the disciplinary sciences, there have been several active disciplinespecific movements, such as Physics education and Biology education research communities. Indeed, the various disciplinary divisions within ASEE have existed for a while as well. CLEERhub is an example of this type of repository funded by NSF which focuses on Engineering Education (https://stemedhub.org/groups/cleerhub). One of the more recent faculty development initiatives, organized by ASEE and sponsored by NSF, Virtual Communities of Practice $^{24}$ (VCPs) aimed to bring together practitioners in specific disciplines with faculty active in the scholarship of teaching and learning in those disciplines. One of the authors participated in the VCP and found it to be useful, but more as an introduction to research-based instructional practices, than a comprehensive resource to walk a practitioner through implementation and evaluation of an innovation. The main issue again was the general context in which most examples of innovative teaching practices were presented. The participants saw the value of various practices such as peer instruction, but found it hard to translate it to the context of their courses, let alone set up an evaluation of its effectiveness. Much like the 'last-mile' problem faced by providers and consumers of high-speed internet, the books and research papers available on research methods, and even on effective instructional practices are inaccessible to most instructors. Switching one's primary field of research to engineering or CS education should not be a prerequisite to understanding, correctly applying, and sharing the results of applying research-based instructional strategies in the classroom.

\section{Pathways for Adoption of Educational Innovations}

Figure 2 illustrates the typical pathways from introduction of an educational innovation to its successful implementation and evaluation. A publication that presents results of testing an innovation in the classroom with valid evaluation methodology not only provides practical benefits for the practitioner (in terms of counting towards scholarship and showcasing the practitioner's dedication to implementing educational innovations in the classroom), but also 


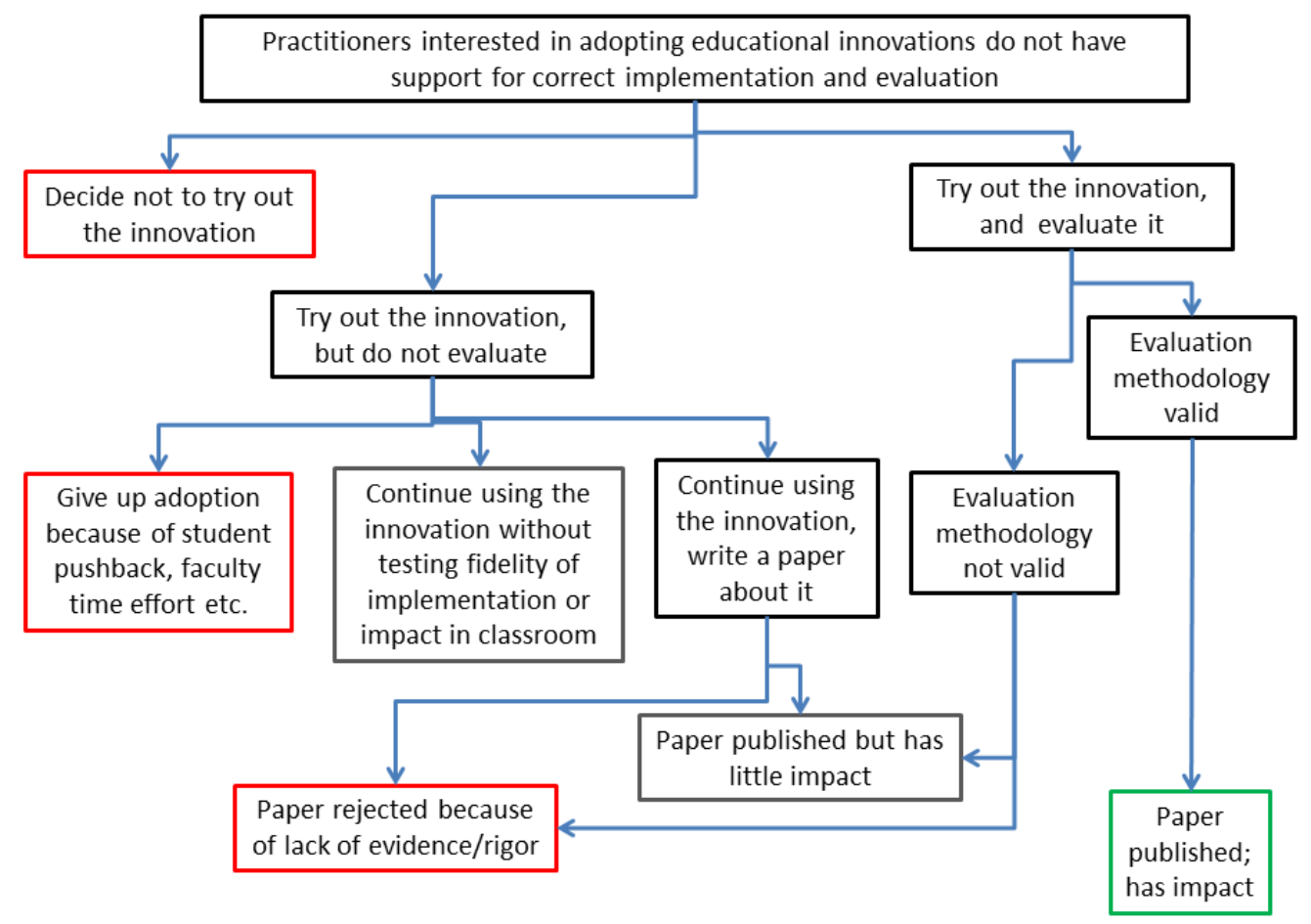

Figure 2: Typical paths taken by a practitioner after being introduced to an educational innovation

furthers the impact of the educational innovation. It furthers the reach of the innovation, and in most cases tests the generalizability and flexibility of the innovation, both of which are critical for broad propagation of the innovation. A number of preconditions exist for the seemingly simple rightmost path in Figure 2, and they stem from the factors listed in Figure 1. Exposure to the innovation, desire to adopt, availability of information on how to implement in the classroom, flexibility of the innovation to fit the practitioner's needs, support for implementing, and the availability of tools for assessing and evaluating the effectiveness of the innovation are the critical factors. We believe that discipline-based and sub-discipline based experts can fill an important gap in the process from exposure to publication, drawing from knowledge in the learning sciences, education, and various other areas including core research in engineering education, and making it accessible to practitioners.

\section{DBER Ambassadors}

A network and community with discipline-based education research experts who serve as the interface between practitioners and the body of knowledge on educational innovations and methods from cognitive science, learning sciences, education research is critical to the adoption of research-based teaching innovations in the classroom. Figure 3 describes a vision of such a network based on the idea of discipline-based education research. The main recommendation we make is a call to action for DBER ambassadors- subject matter experts in engineering disciplines 


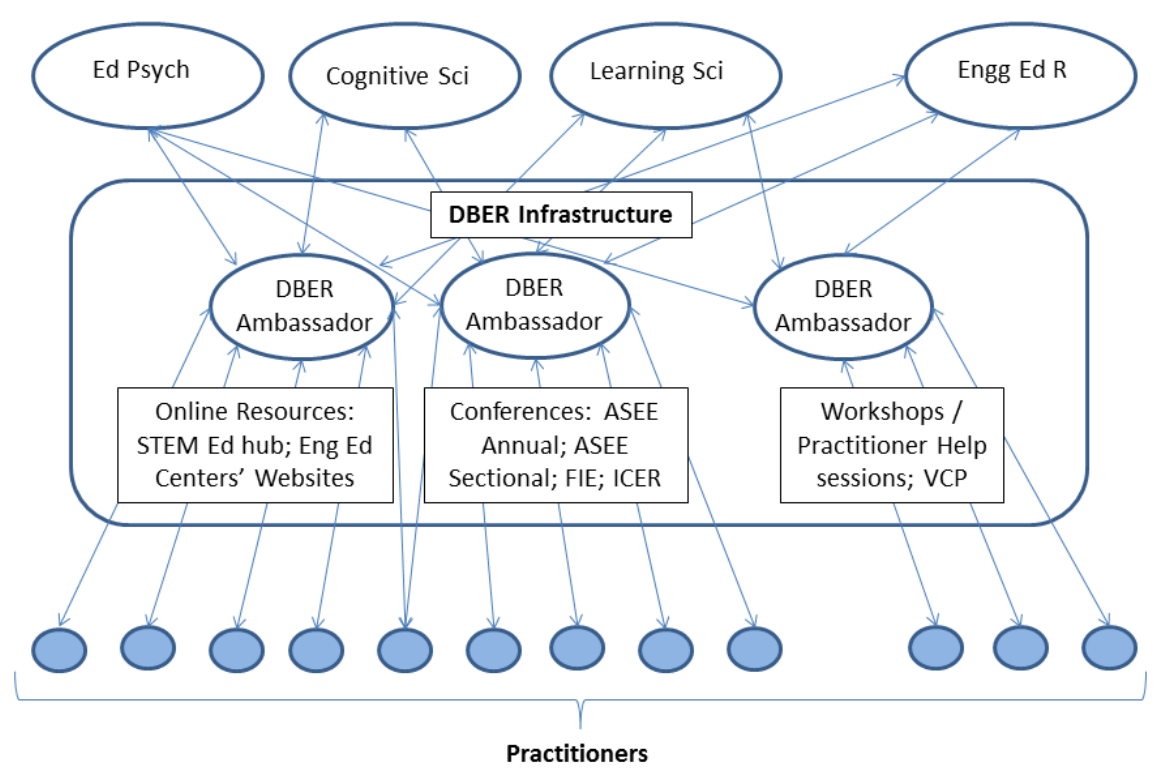

Figure 3: An example of a network led by DBER ambassadors

who can serve as liaisons between practitioners and researchers. These ambassadors may be engineering faculty who have transitioned to research in engineering education, or faculty who have formal training in an engineering discipline as well as in engineering education. Indeed, a majority of the attendees of ASEE's annual conference fit this description, but formally defining the position, and assigning responsibilities, whether it is through the disciplinary divisions of ASEE, or through other ventures such as the VCP, is necessary and will create visibility for the ambassadors. This visibility and formalization is essential because it will be the mechanism for ensuring that practitioners know whom to reach out to, when they decide to adopt and evaluate educational innovations.

Recognition of the role of DBER ambassadors at the intersection of research and service, and formalizing a reward structure for the role is important to attract and retain the ambassadors. Creating the reward structure could be an extension of the current model where service roles in discipline-based divisions within ASEE or other organizations are a natural draw for DBER ambassadors. Engineering departments at various universities (whether R-1 schools or undergraduate-focused institutions) could acknowledge the important role that DBER ambassadors play and could assign recognition towards annual evaluations, tenure, and promotion. Additionally, these departments could provide practitioners release time and professional development support to encourage collaboration with DBER ambassadors to implement pedagogical innovations in their classrooms. As DBER ambassadors work with practitioners to improve the fidelity of implementation of research based instructional innovations, and to write manuscripts on the results of testing these implementations, they would be able to demonstrate strong publications records. The national science foundation, with its stated focus on translation of educational innovations to the classroom, could support DBER 
ambassadors by setting up a program with the express goals of translation and testing the generalizability of educational innovations. In short, the academic system, already has much of the infrastructure and processes to reward DBER ambassadors, but action by the key players is necessary to foster the culture.

\section{Conclusion}

This paper summarizes the reasons for the non-adoption of research-based instructional strategies, focusing on one aspect that has been mostly overlooked by the engineering education community. This aspect is context, i.e. describing the benefits, implementation and evaluation of educational innovations in the appropriate context. Our recommendation is to strengthen discipline-based educational research, with experts in sub-disciplines who can serve as ambassadors or liaisons between practitioners and the educational research communities. These ambassadors will provide mentoring to practitioners, serve as curators of literature and tools that can contextualize well to their disciplines, and will create and maintain resources that will facilitate the adoption and evaluation of educational innovations. The ambassadors can author "guiding papers" that analyze existing literature and introduce evaluation methods in the context that practitioners will find useful. Thus, for the ECE division, we present a brief analysis of a study that was aimed at computer architecture instructors, with a list of lessons learned and some specific recommendations.

\section{References}

1. Fry, C. L. (Ed.) (2014). Achieving Systematic Change: A Source Book for Advancing and Funding Undergraduate STEM Education. Washington, D. C.: The Association of American Colleges and Universities. http://www.aacu.org/pkal/sourcebook

2. Johri, A., \& Olds, B. M. (Eds.). (2014). Cambridge handbook of engineering education research. Cambridge University Press.

3. Besterfield-Sacre, M., Cox, M. F., Borrego, M., Beddoes, K., \& Zhu, J. (2014). Changing engineering education: Views of US faculty, chairs, and deans. Journal of Engineering Education, 103(2), 193-219.

4. Borrego, M., Froyd, J. E., \& Hall, T. S. (2010). Diffusion of engineering education innovations: A survey of awareness and adoption rates in US engineering departments. Journal of Engineering Education, 99(3), 185207.

5. Henderson, C., Finkelstein, N., \& Beach, A. (2010). Beyond dissemination in college science teaching: An introduction to four core change strategies. Journal of College Science Teaching, 39(5), 18-25

6. Matusovich, H. M., Paretti, M. C., McNair, L. D., \& Hixson, C. (2014). Faculty Motivation: A Gateway to Transforming Engineering Education. Journal of Engineering Education, 103(2), 302-330.

7. Augustine, N. R., Barrett, C., Cassell, G., Grasmick, N., Holliday, C., \& Jackson, S. A. (2010). Rising above the gathering storm, revisited: Rapidly approaching category 5. Washington, DC: National Academy of Sciences, National Academy of Engineering, Institute of Medicine. 
8. Feser, J., Borrego, M., Pimmel, R., \& Della-Piana, C. (2012). Results from a survey of National Science Foundation Transforming Undergraduate Education in STEM (TUES) program reviewers. In ASEE Annual Conference \& Exposition, San Antonio, TX.

9. NRC (2012). National Research Council, Discipline-based Education Research: Understanding and Improving Learning in Undergraduate Science and Engineering. Washington, DC: National Academies Press,

10. Henderson, C., \& Dancy, M. H. (2007). Barriers to the use of research-based instructional strategies: The influence of both individual and situational characteristics. Physical Review Special Topics - Physics Education Research, 3(2), 020102.

11. Lattuca, L. R. (2011, February). Influences on engineering faculty members' decisions about educational innovations: A systems view of curricular and instructional change. In Proc. Forum Impact Diffusion Transform. Eng. Educ. Innov.

12. William R.. Shadish, Cook, T. D., \& Campbell, D. T. (2002). Experimental and quasi-experimental designs for generalized causal inference. Wadsworth Cengage learning.

13. Fairweather, J. (2008). Linking evidence and promising practices in science, technology, engineering, and mathematics (STEM) undergraduate education.Board of Science Education, National Research Council, The National Academies, Washington, DC.

14. Jamieson Leah, H. (2012). Innovation with Impact [Electronic resource]: Creating a culture for scholarly and systematic innovation in engineering education/Leah H. Jamieson and Jack R. Lohmann. Amer. Soc. for Eng. Education (ASEE).-Washington, DC.

15. Henderson, C., \& Dancy, M. H. (2008). Physics faculty and educational researchers: Divergent expectations as barriers to the diffusion of innovations. American Journal of Physics, 76(1), 79-91.

16. Mulia, W. D., Fritz, D. J., Sohoni, S. A., Kearney, K., \& Mwavita, M. (2013). PLP: A community driven open source platform for computer engineering education. International Journal of Engineering Education, 29(1), 215-229.

17. Digilent Nexys3 Spartan-6 FPGA Board (2016, February). Retrieved from http://www.digilentinc.com/Products/Detail.cfm?Prod=NEXYS3.

18. Kruger, J., \& Dunning, D. (1999). Unskilled and unaware of it: How difficulties in recognizing one's own incompetence lead to inflated self-assessments. Journal of Personality \& Social Psychology, 77, 1121-34.

19. Commander, N. E., \& Stanwyck, D. J. (1997). Illusion of knowing in adult readers: Effects of reading skill and passage length. Contemporary Educational Psychology, 22(1), 39-52.

20. Glenberg, A. M., Wilkinson, A. C., \& Epstein, W. (1982). The illusion of knowing: Failure in the selfassessment of comprehension. Memory \& Cognition, 10(6), 597-602.

21. Clark, R. E., Feldon, D., van Merriënboer, J. J., Yates, K., \& Early, S. (2008). Cognitive task analysis. Handbook of research on educational communications and technology, 3, 577-593.

22. Lohmann, J., \& Froyd, F. (2010). Chronological and ontological development of engineering education as a field of scientific inquiry. In Second Meeting of the Committee on the Status, Contributions, and Future Directions of Discipline-Based Education Research, Washington, DC. http://www.nap.edu/catalog.php? record_id=13362

23. Singer, S. R., Nielsen, N. R., \& Schweingruber, H. A. (Eds.). (2012). Discipline-based education research: understanding and improving learning in undergraduate science and engineering. National Academies Press.

24. ASEE VCP (2016, February), ASEE’s Virtual Communities of Practice. Retrieved from http://www.asee.org/ASEE-VCP 


\section{Appendix A: Pre-Posttest}

Name:

\section{Demographics questions:}

1. What is your classification? (sophomore, junior, senior...)

2. Have you participated in any courses that have required you to work in teams? If yes, which ones?

3. Have you written any computer programs? If yes, which programming languages have you used?

Perception survey:

4. Given a choice between designing hardware or software what would you pick?

- Hardware

- Software

- I like both equally

- I don't know enough to choose

5. How would you rate your interest in Computer Engineering on a scale of 1-5? (5 being the highest)

6. Do you plan to pursue gradate studies in Electrical or Computer Engineering?

Knowledge assessments: Familiarity

7. Of the following words, please mark all those that you are familiar with

- Logic Gate

- Arithmetic Logic Unit

- D Flip-Flop

- Hexadecimal

- Register File

- ROM (Read Only Memory)

- Data Structures

- RISC/CISC

- Pipelining
- Boolean Logic

- I/O Port

- CPU Registers

- CMOS

- Latency

- Throughput

- Verilog/VHDL

- Datapath

- Cache

Knowledge assessments: Prerequisite knowledge

9. List the main parts of a microprocessor.

10. $8 \mathrm{~b} 30$ is the machine code to add 48 to register A. How does the microprocessor know to perform this action based on the instruction?

11. What is the result of 0110 AND 0011? 0110 XOR 0011?

12. A state machine with 4 state bits has at most how many possible states?

Knowledge assessments: Course knowledge

13. The instruction fetch stage uses with of these buses: Data bus, Address Bus, Control Bus?

14. Define latency.

15. Define throughput.

16. How does pipelining potentially improve the throughput of a processor?

17. What are the three busses in any digital computer system?

18. What are the three or five blocks in any digital computer system? 


\section{Appendix B: Guiding Questions for Focus Group Interviews}

- How does your learning experience in the class compare with other learning experiences in your other engineering coursework?

- In what ways were you able to link learning from other classes to this one?

- How would you describe your interest level within and across the time of this class?

- Describe the level of collaboration that was required with your classmates.

- In what aspects did this class help you to prepare to work in engineering in the "real world?" 